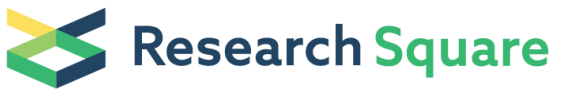 \\ Preprints are preliminary reports that have not undergone peer review. \\ They should not be considered conclusive, used to inform clinical practice, or referenced by the media as validated information.
}

\section{Why online medical teams disband? The role of team diversity and leadership type}

Jiaying Li

Huazhong University of Science and Technology

Hong Wu

Huazhong University of Science and Technology

Zhaohua Deng ( $\nabla$ zh-deng@hust.edu.cn)

Huazhong University of Science and Technology https://orcid.org/0000-0002-7744-7818

Richard Evans

Brunel University

Ziying Hong

Huazhong University of Science and Technology

Shan Liu

Xi'an Jiaotong University

\section{Research article}

Keywords: Online health community; Online medical teams; Virtual teams; Team diversity; Leadership types; Team disbandment.

Posted Date: August 19th, 2019

DOI: https://doi.org/10.21203/rs.2.13131/v1

License: (1) This work is licensed under a Creative Commons Attribution 4.0 International License. Read Full License

Version of Record: A version of this preprint was published at Information Technology \& People on May 28th, 2020. See the published version at https://doi.org/10.1108/ITP-10-2019-0534. 


\section{Abstract}

Background Medical teams (MTs) online can provide comprehensive and rapid healthcare services to patients through doctors' collaboration. The growth of MTs continues with their increasing popularity among doctors and patients, but there also exists some disbanded MTs, which would break the continuity of healthcare services. We aim to addressing this pressing issue by exploring effects of team diversity and leadership types on the team status (i.e. team disbandment). Specifically, we classify team diversity into separation diversity, variety diversity and disparity diversity, and leadership types based on the clinical titles include strong, equal and weak types. Methods A dataset of 1,071 MTs online were traced from the Good Doctor Online, a leading online health community (OHC) in China on January 10, 2018, and 206 teams disbanded after 3 months. Logistic regression and Maximize Likelihood Estimation were used to examine their effects. Results Our findings suggest that variety diversity related to the departments positively affected team disbandment, but disparity diversity referring to the clinical titles negatively affected team disbandment. Separation diversity in terms of the members' attitude exerted a negligible influence on team disbandment. Although strong and equal leadership negatively influenced team disbandment, they strengthened the positive effect of variety diversity, suggesting the stable structure matching of strong/equal-type leadership and low department diversity, and the matching of weak-type leadership and high department diversity. Conclusion This study focuses on effects of leadership types and team diversity, and their pairwise combinations are obtained to effectively reduce the disbandment probability of medical teams in OHCs. It could help platforms, team founders, and all those connected with MTs positively deal with the team disbandment crisis. Theoretical and practical implications in OHCs and limitations were discussed.

\section{Background}

Online medical teams (MTs), a novel form of healthcare service, emerged in online health communities (OHCs) in 2017. With the increasing popularity, as of early 2019 , more than 3000 MTs employing over 10,000 doctor members have existed in China. To some extent, online MTs can alleviate the current imbalance between medical supply and demand in China. On one hand, doctors can improve the service responsiveness and optimize the resource allocation through communicating and cooperating with others in MTs, subsequently alleviating supply issues such as human resource shortage in healthcare services. On the other hand, population aging and rising living standard have triggered the soaring demands for healthcare service [1], and MTs in OHCs can meet these high requirements by increasing/improving both of service quantity and quality.

MTs online have been considered theoretically promising because of their advantages, but prompt solutions of serious disbandment issues are needed in practice. According to our data obtained from OHCs, approximately $20 \%$ of MTs have disbanded and the number is continuously increasing. Team disbandment (TD) can not only affect the continuity of medical services from a patient's perspective, but also worsen the relationships between participating doctors and OHCs, subsequently affecting the supply of healthcare services online. In brief, TD would have serious negative influences on healthcare services in OHCs.

Virtual teams are hard to run efficiently because their operation and management are complex [2], so are MTs online. Most doctors are inexperienced in the team establishment, so their MTs face the risk of disbandment. Once members feel the lack of improvement and have few constraints on leaving, they may collectively choose to leave [3]. In particular, when members prefer other forms of online healthcare services such as written/telephone consultation to MTs, they would even deny the value of team-based services, so TD largely depends on the features of leadership and members.

The dearth of research on MT disbandment is noteworthy, given the recent calls for examining its factors to adopt effective adjustments. Existing studies on virtual teams mostly focus on team performance in other fields $[4,5]$. Quantified empirical analyses to understand TD's actual impact factors are usually disregarded and related researches are scarce, mainly because most virtual teams are temporary and their disbandment is based on task completion [6] without the need for further studies. Whereas, MTs in OHCs are long-term and their disbandment should be empirically investigated to achieve the sustainable development.

Studies have focused on the effects of team leadership, team diversity on virtual team performance [7-9]. Some scholars summarized 24 studies on team diversity, concluding that diversity can significantly affect team output/performance in most cases [10]. Given that diversity may lead to conflict and negative effects on team-based services $[7,11,12]$, it can further influence team status and result in TD. Second, the critical roles of leadership in a team have been confirmed [13]. In the context of MTs, leaders should not only consider the coordination of members, but also adjust a team and improve its adaptability in the face of challenges such as the disbandment and members' withdrawal. Since the related potential mechanisms are still unclear, we would study the following research questions: 
(2) How does leadership type affect MT disbandment?

This study mainly investigates the influences of leadership types and team diversity on the disbandment of online MTs. It is organized as follows. We introduce the literature review in the second part and the model hypotheses in the third part. Then, we describe the methods and results in the fourth and fifth parts, respectively. Implications and conclusions of this study are discussed in the sixth part.

\section{Literature Review}

\section{Medical teams and leadership type in OHCs}

Group work is an essential part of modern health care $[14,15]$. MTs, composed of a founder and other members, such as nurses, medical technicians or doctors, provide the "several-to-one" healthcare consultation for a patient in an OHC platform through communication equipment, thereby realizing both doctor-doctor and doctor-patient communication. MTs are characterized by member dispersion and team virtuality, which are also two principal characteristics of virtual teams [16]. Studies on virtual teams have covered different fields, such as open-source software teams, top management teams, and research and development teams in international corporations [4, 5]. Only a few studies have explored online MTs [9, 17], and confirmed the important role of the leader and members in team output from the transactive memory perspective [17].

Leadership plays a crucial role in adjusting a team to adapt well, especially when it faces obstacles and challenges such as member withdrawal or TD [18-20]. Various types of leadership function differently [21-23], so it is indispensable for to divide online MTs into three coordination modes: integrated, assistant, and independent. In the assistant mode, the leader is considered dominant over members; in the two other modes, the leader and members are regarded equally [17]. However, this classification ignores the existence of the weak-type leadership, so we divide leadership into three types: strong, equal and weak (Figure 2) by comparing clinical titles of team leader and members.

\section{Team diversity}

Scholars have classified team diversity and studied its effect on team performance [10,24, 25]. Effects of diversity on team output/performance are inconclusive [26, 27], and a typical resolution is to divide it into different sub-concepts[28]. Informational diversity referring to task and social category diversity focusing on social demographic indicators should be a common classification [29]. However, given the particularity of online MTs and medical services, we choose the classification of separation, variety and disparity diversity [26]. Specifically, separation diversity focuses on the inconsistency or opposition of members in subjective aspects such as attitude, which can be reflected by the response timeliness of doctors, as the more positive a doctor in OHCs is, the faster his/her response to a patient will be. Variety diversity highlights members' differences in professional skills/knowledge and information, which corresponds to distinctive departments in the medical field. Disparity diversity emphasizes the difference in the vertical continuum of status or power among members. In the $\mathrm{OHC}$ context, patients tend to trust doctors with a high status [30], and the main indicator of doctors' status capital is clinical title [31], so the difference in members' clinical titles could represent disparity diversity.

\section{Team disbandment}

Fragile virtual teams are prone to disband, but their features and the disbandment reasons remain to be explored. MTs in OHCs have existed in China for almost 2 years, and some teams have disbanded with the increasing number of teams, since members may collectively choose to leave when they feel improvement is unlikely and have few constraints on leaving [3]. Scholars investigated the effect of organizational differences on the technology abandonment from a negative perspective [32], so we also focus on TD from the negative perspective. Factors of TD, especially organizational characteristics and leadership, have been explored [33, 34]. Based on these points, team diversity and leadership type could affect TD of MTs in OHCs

\section{Research Model And Hypotheses}

This dissertation focuses on team diversity and leadership types to explore different team states on the basis of extensive literatures on virtual teams $[6,18,35]$. Team diversity often leads to social loafing among members [36]. Team leadership plays a key role in dealing 
with crises such as disbandment $[18,19]$. Thus, we investigate the disbandment issue of MTs from these two perspectives based on related researches [8]. The conceptual model is shown in Figure 1.

\section{Team diversity and team disbandment}

As a whole, given the negative effects of team diversity on team-based services [26], diverse teams likely disband. members possibly think that their contribution is non-essential in a diverse team, then reducing dispensable efforts; meanwhile, others would also reduce their effort to avoid the "sucker effect" caused by free riders' exploitation [37, 38]. Eventually, this free-riding behavior would lead to the loss of team-based services and a vicious cycle among members in MTs.

Separation diversity, referring to the subjective attitude of doctors in MTs, can decrease the cohesion among team members, subsequently causing performance to decline [39] and TD. Differences in members' attitudes can cause distrust and conflicts among members, leading to decreased contribution and even withdrawal of some members [26]. This finding is consistent with the conclusion of social loafing in team research [36]. Thus, we develop the following hypothesis:

\section{Hypothesis 1a: Separation diversity is a risk factor of the disbandment of MTs.}

In view of the high professionalism in the medical field, variety diversity of members' departments affects the perceived professionalism and disbandment of a team. People tend to choose professional healthcare services [31] and seek the help of MTs online purposefully. Considering medical experience, homogeneous teams, which likely have a professional impression, can attract and retain more patients than diverse teams do. Only in this virtuous cycle can members be motivated to continue to provide services as a team, and vice versa. Thus, the following assumption is developed:

\section{Hypothesis 1b: Variety diversity is a risk factor of the disbandment of MTs.}

Disparity diversity in the MT context affects the team status (i.e., whether or not to disband) through the service speed. Medical services unlike other services refer to the life and sufferings of patients, extremely requiring timeliness. In fact, doctors with high clinic titles are busy with services offline, leaving less time for services online, and doctors with low clinic titles usually have enough time online, so differences in members' status result in their complementarity in time. In addition, previous studies have confirmed that disparity could positively affect outcomes by accelerating decision-making [40,41]. Thus, given the patients' urgent need for access to medical services and relief from disease pain, the negative effect of social loafing among members is secondary to positive effects of time complementarity. Thus, we predict:

\section{Hypothesis 1c: Disparity diversity is a protective factor of the disbandment of MTs.}

\section{Team leadership type and team disbandment}

Previous studies have examined the key role of leadership in team functioning and confirmed the different influences of leadership types on team state [22]. Especially, the timely adjustment of leaders is necessary while facing challenges [18, 19], and TD usually results from the team's inability. First, MTs with different leaders have different levels of adaption ability to remove obstacles, and among three leadership types, the weak-type leader is weak in clearing obstacles or adapting to challenges, so it is most likely to disband. Furthermore, members prefer the strong-type leadership to form a relatively stable structure, since a person's behavior is dictated by social norms [42] and an implicit social norm suggests that people are willing to obey to authority [43]. Finally, equal-type leadership mode is conducive to form the loose, flexible and democratic atmosphere, where the MT can be easily adjusted to promote the virtuous circle of service and avoid disbandment. Following this logic, we test the following:

\section{Hypothesis 2a (2b): The strong-type (equal-type) leadership is a factor that prevents TD, that is the MT with strong-type (equal-type) leadership is not easy to disband compared with that of the weak type.}

\section{Moderating effect of leadership types}

Evidence suggests that team diversity has significant interaction effects with leaders' experience and characteristics [44-46], indicating that the effect of team diversity varies with leadership types. Doctors' high level of clinical title in China suggests the rich clinical experience, so leadership types defined according to the clinical title can reflect doctors' experience to some extent. Following this logic, it could have remarkable interaction effect with team diversity. Moreover, considering the social compensation among members [36], different leadership types need different compensation degree, so they pairwise combine with different team diversity. Weak-type 
leaders tend to compensate for their own weakness by increasing diversity to reduce the TD possibility. However, strong/equal-type leaders are different from a weak-type leadership in MTs, since they look for equal or less experienced doctors as members and subjectively do not need the social compensation from others based on the leadership classification and actual situations.

Effects of team diversity on TD changes with leadership types. First, as separation diversity may lead to conflicts or social loafing among members and strong-type leaders usually tend to be busy with medical services offline, these MTs are more likely to lack cohesion and then disband than those with a weak-type leadership. Second, members from diverse departments are indispensable for the weak-type leader, so social compensation exists in these MTs, but high variety diversity are redundant for the other leadership types. Third, given that disparity diversity and strong-type leadership are protective factors against TD, their synergistic effects are essential for the stability of MTs. Thus, we predict the following:

Hypothesis 3: The strong-type leadership positively moderates the relationship between team diversity (i.e., separation diversity (3a), variety diversity (3b), and disparity diversity (3c)) and TD compared with that of the weak-type leadership.

Equal-type leaders function similarly, mainly because they seem relatively dominant compared with weak-type leaders. Equal-type leaders exhibit flexibility to adjust team diversity, so they can positively moderate the relationship between team diversity and team status. Thus, we hypothesize the following:

Hypothesis 4: The equal leadership type positively moderates the relationship between team diversity (i.e., separation diversity (4a), variety diversity (4b), and disparity diversity (4c)) and TD compared with that of the weak-type leadership.

\section{Methods}

\section{Sample and data collection}

We tested our conceptual model in a sample of 1,071 MTs. In this study, data of MTs were crawled from the Good Doctor Online (i.e., www.haodf.com/), one of the leading OHCs in China. We studied the change in the status of these teams (whether the team disbanded or not) during a 3-month period from January 10, 2018, to April 10, 2018, and 1,071 MTs were available online on January 10, 2018, so the sample was 1,071 MTs and 4,740 doctor members. The measurement of variables in the empirical models was explained in Table 1.

Table 1. Descriptive statistics. 


\section{Dependent variables}

Team_status $\quad 1$ if a medical team disbanded; 0 otherwise.

Independent

variables

Diversity

constructs

Separation The standard deviation of all members' response speed

Interval

Variety The total number of the doctor departments in a MT

Interval

Disparity

The standard deviation of doctors' clinic titles in a MT. Clinic titles include four levels:

Interval

Resident/Attending/Associate Chief/Chief Doctor from low to high level and the corresponding value is from 1 to 4.

\section{Leadership type}

LTypedummy1

1 if the title of team leader is highest among all members (strong-type leadership); 0 otherwise.

Dummy

LTypedummy2

1 if the title of team leader is equal to the title of any member in medical team (equal-type leadership); 0 otherwise.

Dummy

Control variables

TeamSize

The number of team members

Interval

ResponseSpeed

Response speed of the team-based written consultation

Interval

InitialServiceQuantity

The initial service quantity of a MT

Interval

Price

\section{Measurement}

Dependent Variable. The dependent variable in this study was the status of the MT. The value was 1 when a team disbanded, and the value of undissolved teams was 0 . Among the 1,071 MTs, 206 MTs disbanded, accounting for nearly $20 \%$.

Independent Variables. Team diversity and leadership types were two aspects of explanatory variables. Team diversity included separation, variety, and disparity. Separation was mainly reflected by the standard deviation of doctors' attitude toward healthcare service in OHCs, namely, the response speed of individual service. Variety was determined by the number of departments and the status Disparity was demonstrated by the standard deviation of team members' clinical titles. Leadership in MTs can be classified into three categories: strong, equal and weak-type. When the level of leader title was higher than the title levels of other members, the team was defined as strong-type leadership, and the corresponding variable was LTypedummy1. When the level of leader title equaled that of any other member, the MT belonged to an equal leadership type, and the dummy variable was LTypedummy2. When the level of leader title was lower than that of the other members, the MT leadership was weak (Figure 2). The formula for two dummy variables of leadership types was as follows (see Formula in Supplementary Files)

Control Variables. Control variables included indicators of team and team-based service such as team size, response speed, initial service quantity and price. Evidence suggested that team size and early stage team activities could affect the team status [17, 47], so we controlled related variables.

\section{Empirical models}

The dependent variable was the status of the MT. The status value of the MT in the disbandment state was 1 , and the status value of the MT that did not disband was 0 . Considering that the dependent variable was a binary variable, we used logistics regression to test the hypothesis. Our final empirical models were as follows, and $\beta_{0}-\beta_{15}$ were the parameters we would estimate, represented the random error term and $p$ represented the probability of TD. (see Equation in Supplementary Files) 


\section{Results}

Logistic regression was conducted to test the hypotheses. Maximum likelihood estimation (MLE) was performed to estimate empirical results, and $p<0.05$ was considered statistically significant. Data were analyzed using STATA.

\section{Descriptive statistics and correlations}

Descriptive statistics and Pearson correlations for all variables were presented in Table 2. The mean value for status of the MT was 0.19 , which indicated that approximately $20 \%$ of all MTs studied in this paper disbanded during the 3-month period. The VIF value of all variables were less than 10 , so we could ignore multicollinearity [48].

Table 2. Descriptive statistics (including Pearson correlations) $(\mathrm{N}=1071)$.

\begin{tabular}{|c|c|c|c|c|c|c|c|c|c|c|c|c|c|c|}
\hline Variables & Min. & Max. & Mean & S.D. & VIF & (1) & (2) & (3) & (4) & (5) & (6) & (7) & (8) & (9) \\
\hline (1) Status of the MT & 0 & 1 & 0.19 & 0.39 & - & & & & & & & & & \\
\hline (2) Separation & 0 & 0.5 & 0.31 & 0.17 & 1.082 & 0.038 & & & & & & & & \\
\hline (3) Variety & 1 & 21 & 1.62 & 1.31 & 1.438 & $0.393^{* *}$ & $0.106^{* *}$ & & & & & & & \\
\hline (4) Disparity & 0 & 1.9 & 0.31 & 0.19 & 1.398 & $-0.166^{* *}$ & $0.090^{* *}$ & $-0.138^{* *}$ & & & & & & \\
\hline (5) LTypedummy1 & 0 & 1 & 0.59 & 0.49 & 3.468 & $-0.319^{* *}$ & -0.055 & $-0.321^{* *}$ & $0.432^{* *}$ & & & & & \\
\hline (6) LTypedummy2 & 0 & 1 & 0.32 & 0.47 & 3.294 & $0.153^{* *}$ & 0.060 & $0.231^{* *}$ & $-0.420^{* *}$ & $-0.827^{* *}$ & & & & \\
\hline (7) TeamSize & 2 & 24 & 4.43 & 2.80 & 1.582 & $0.205^{* *}$ & $0.248^{* *}$ & $0.492^{* *}$ & $0.118^{* *}$ & $-0.269^{* *}$ & $0.246^{* *}$ & & & \\
\hline (8) ResponseSpeed & 0 & 1 & 0.41 & 0.44 & 1.097 & -0.053 & $0.083^{* *}$ & 0.039 & 0.021 & -0.042 & $0.060^{*}$ & $0.120^{* *}$ & & \\
\hline (9) & 0 & 636 & 12.21 & 32.18 & 1.097 & $-0.064^{*}$ & 0.034 & 0.019 & $0.101^{* *}$ & 0.018 & -0.024 & $0.106^{* *}$ & $0.272^{* *}$ & \\
\hline \multicolumn{15}{|l|}{ InitialServiceQuantity } \\
\hline (10) Price & 9 & 800 & 82.23 & 88.32 & 1.020 & 0.041 & $0.106^{* *}$ & $0.078^{*}$ & 0.019 & -0.018 & 0.006 & $0.101^{* *}$ & 0.037 & 0.0 \\
\hline
\end{tabular}

Notes: **. Correlation is significant at the 0.01 level (2-tailed); *. Correlation is significant at a 0.05 level (two tailed).

Table 3. Results of Hierarchical Logistic Regression (N=1071). 


\begin{tabular}{|c|c|c|c|c|c|c|c|c|}
\hline \multirow{2}{*}{ Variables } & \multicolumn{2}{|c|}{ Model 1} & \multicolumn{2}{|l|}{ Model 2} & \multicolumn{2}{|l|}{ Model 3} & \multicolumn{2}{|l|}{ Model 4} \\
\hline & coefficient & $\operatorname{Exp}(B)$ & coefficient & $\operatorname{Exp}(B)$ & coefficient & $\operatorname{Exp}(B)$ & coefficient & $\operatorname{Exp}(\mathrm{B})$ \\
\hline Intercept & $-2.083(0.170)^{* * *}$ & 0.125 & $-2.185(0.264)$ & 0.113 & $-0.610(0.346)^{*}$ & 0.544 & $1.256(0.732)^{*}$ & 3.512 \\
\hline TeamSize & $0.182(0.027)^{* * *}$ & 1.199 & $0.087(0.038)^{* *}$ & 1.091 & $0.063(0.040)$ & 1.065 & $0.062(0.041)$ & 1.064 \\
\hline ResponseSpeed & $-0.248(0.199)$ & 0.781 & $-0.306(0.217)$ & 0.736 & $-0.307(0.222)$ & 0.736 & $-0.331(0.225)$ & 0.718 \\
\hline InitialServiceQuantity & $-0.016(0.006)$ & 0.984 & $-0.013(0.006)^{* *}$ & 0.987 & $-0.012(0.006)^{* *}$ & 0.988 & $-0.013(0.006)^{* *}$ & 0.987 \\
\hline Price & $0.000(0.001)$ & 1.000 & $0.000(0.001)$ & 1.000 & $0.000(0.001)$ & 1.000 & $0.000(0.001)$ & 1.000 \\
\hline Separation & & & $-0.035(0.540)$ & 0.966 & $-0.009(0.561)$ & 0.991 & $-2.781(1.396)^{* *}$ & 0.062 \\
\hline Variety & & & $0.694(0.083)^{* * *}$ & 2.001 & $0.603(0.086)^{* * *}$ & 1.828 & $0.251(0.157)^{*}$ & 1.285 \\
\hline Disparity & & & $-2.217(0.561)$ & 0.109 & $-1.456(0.646)^{* *}$ & 0.233 & $-2.470(1.670)^{*}$ & 0.085 \\
\hline LTypedummy1 & & & & & $-2.044(0.277)^{* * *}$ & 0.130 & $-4.636(0.897)$ & 0.010 \\
\hline LTypedummy2 & & & & & $-1.432(0.276)^{* * *}$ & 0.239 & $-3.554(0.814)$ & 0.029 \\
\hline LTypedummy $1 *$ Separation & & & & & & & $2.877(1.661)^{*}$ & 17.762 \\
\hline LTypedummy $2 *$ Separation & & & & & & & $3.715(1.646)^{* *}$ & 41.057 \\
\hline LTypedummy $1 *$ Variety & & & & & & & $0.861(0.239)^{* * *}$ & 2.365 \\
\hline LTypedummy $2 *$ Variety & & & & & & & $0.304(0.183)^{*}$ & 1.355 \\
\hline LTypedummy $1 *$ Disparity & & & & & & & $0.833(1.959)$ & 2.300 \\
\hline LTypedummy2* Disparity & & & & & & & $1.470(1.877)$ & 4.350 \\
\hline -2Log likelihood & 991.707 & & 863.130 & & 809.496 & & 788.158 & \\
\hline Chi-square & 57.023 & & 185.601 & & 239.234 & & 260.573 & \\
\hline Correct Percentage & 0.814 & & 0.824 & & 0.836 & & 0.840 & \\
\hline
\end{tabular}

Notes: $N=1071$. Standard errors are in parentheses. MLE. ${ }^{*} \mathrm{p}<0.1{ }^{* *} \mathrm{p}<0.05 .{ }^{* * *} \mathrm{p}<0.01$.

Table 4. Robustness Test Results ( $N=993)$.

\begin{tabular}{|c|c|c|c|c|c|c|c|c|}
\hline \multirow[t]{2}{*}{ Variables } & \multicolumn{2}{|c|}{ Model 1} & \multicolumn{2}{|l|}{ Model 2} & \multicolumn{2}{|c|}{ Model 3} & \multicolumn{2}{|c|}{ Model 4} \\
\hline & coefficient & $\operatorname{Exp}(B)$ & coefficient & $\operatorname{Exp}(B)$ & coefficient & $\operatorname{Exp}(B)$ & coefficient & $\operatorname{Exp}(B)$ \\
\hline Intercept & $-1.837(0.174)^{* * *}$ & 0.159 & $-1.809\left(0.271_{* * *}\right)$ & 0.164 & $-0.305(0.354)$ & 0.737 & $1.463(0.746)^{*}$ & 4.320 \\
\hline TeamSize & $0.174(0.027)^{* * *}$ & 1.190 & $0.080(0.038)^{*}$ & 1.083 & $0.059(0.040)^{*}$ & 1.061 & $0.059(0.041)$ & 1.061 \\
\hline ResponseSpeed & $-0.423(0.200)$ & 0.655 & $-0.488(0.218)^{*}$ & 0.614 & $-0.480(0.224)^{*}$ & 0.619 & $-0.494(0.226)$ & 0.610 \\
\hline InitialServiceQuantity & $-0.018_{* * *}(0.006)$ & 0.982 & $\begin{array}{r}-0.015(0.007) \\
* *\end{array}$ & 0.985 & $-0.014(0.007)^{* *}$ & 0.986 & $-0.015(0.006)$ & 0.986 \\
\hline Price & $0.000(0.001)$ & 1.000 & $0.000(0.001)$ & 1.000 & $0.000(0.001)$ & 1.000 & $0.000(0.001)$ & 1.000 \\
\hline Separation & & & $-0.534(0.560)$ & 0.586 & $-0.476(0.584)$ & 0.622 & $-2.691(1.412)$ & 0.068 \\
\hline Variety & & & $0.699(0.084)$ & 2.012 & $0.610(0.088)^{* * *}$ & 1.841 & $0.255(0.159)^{*}$ & 1.291 \\
\hline Disparity & & & $-2.182(0.566)$ & 0.113 & $-1.475(0.651)^{*}$ & 0.229 & $-2.764(1.696)$ & 0.063 \\
\hline LTypedummy1 & & & & & $-1.986(0.281)^{* * *}$ & 0.137 & $-4.500(0.906)$ & 0.011 \\
\hline LTypedummy2 & & & & & $-1.389(0.281)^{* * *}$ & 0.249 & $-3.361(0.828)$ & 0.035 \\
\hline LTypedummy $1 *$ Separation & & & & & & & $2.259(1.695)$ & 9.578 \\
\hline LTypedummy2* Separation & & & & & & & $2.294(1.682)^{*}$ & 19.096 \\
\hline LTypedummy 1 *Variety & & & & & & & $0.871(0.244)$ & 2.388 \\
\hline LTypedummy $2 *$ Variety & & & & & & & $0.299(0.186)^{*}$ & 1.349 \\
\hline LTypedummy 1 * Disparity & & & & & & & $1.182(1.972)$ & 3.260 \\
\hline LTypedummy2* Disparity & & & & & & & $1.829(1.910)$ & 6.226 \\
\hline -2Log likelihood & 954.948 & & 828.051 & & 778.263 & & 759.367 & \\
\hline Chi-square & 59.027 & & 185.924 & & 235.712 & & 254.608 & \\
\hline Correct Percentage & 0.819 & & 0.819 & & 0.834 & & 0.835 & \\
\hline
\end{tabular}

Notes: $N=$ 993. Standard errors are in parentheses. MLE. ${ }^{\star} p<0.1 .{ }^{\star \star} p<0.05 .{ }^{\star \star \star} p<0.01$. 
The influences of most variables were significant. To test the hypotheses of the proposed model, we considered five models. First, we only tested the effects of control variables in Model 1. Furthermore, we respectively added Team Diversity and leadership types in Model 2 and Model 3, where we evaluated $\mathrm{H} 1$ and $\mathrm{H} 2$. Finally, we built their interaction and tested $\mathrm{H} 3$ and $\mathrm{H} 4$, and results were shown in Table 3. Hypothesis 1 was partially supported because Hypothesis 1a was not supported. Hypothesis $1 \mathrm{~b}$ and Hypothesis $1 \mathrm{c}$ were supported. Results supported Hypothesis 2, both Hypothesis 2a and Hypothesis 2b. Hypothesis 3 included three hypotheses, and only Hypothesis $3 \mathrm{~b}$ was supported. Results partially supported Hypothesis 4 since only Hypothesis $4 \mathrm{~b}$ was supported. Among the control variables, team size was a risk factor of TD. Response speed and price had no significant influence on TD. Initia/ServiceQuantity was the protective factor of TD.

Factors had both direct and indirect influences on TD. First, considering the direct influence, Separation Diversity had no significant influence on TD. Variety Diversity and the weak-type leadership were the risk factors of TD. Disparity Diversity and strong/equal-type leadership were the protective factors against TD. Second, considering the moderating effect, the interaction between Disparity Diversity and leadership types had no significant effect on TD. As separation had no significant influence on TD, we disregarded its interaction with leadership types. Thus, leadership types only significantly affected the relationship between Variety Diversity and TD, and strong/equal-type leadership enhanced the positive effect of Variety Diversity on TD, suggesting that MTs with strong/equal-type leadership should have fewer departments. Following the same logic, MTs online with multiple departments and weak-type leadership were less likely to disband.

\section{Robustness tests}

We selected the method of eliminating the extreme values by using a part of the total samples to test the robustness of results. We aimed to study the MTs online that had used this service form, so teams that did not provide team-based service were excluded from samples, and we ran models by disregarding teams whose initial service quantity was 0 . We also used the logistic regression to test whether the result was robust. Among these MTs, 78 teams had zero initial service quantity, and the remaining 993 teams had ever provided team-based services. Results were robust according to variable coefficients, odds ratios and significance levels in Table 4.

\section{Discussion}

\section{Implications}

This study contributes to theories as follows. First, this investigation is unique because it empirically studies actual MTs from a reverse perspective and produces several insights, which have implications for TD, MTs, OHCs and intellectual-intensive team literature. Second, team diversity and leadership offer insights into the potential mechanisms underlying the observed disbandment in MT, and their classifications in this investigation could help researchers and practitioners understand how MTs function. Third, some theories in other fields such as social norm theory, social loafing, social compensation, informational/normative influence, have been applied to investigate online MTs, verifying their generality in TD of MTs and enriching the theoretical basis for OHC research.

In practice, the significance of team design has been highlighted [33,49], and this dissertation could provide suggestions for team founders/leaders and platform about MTs' design in OHCs such as team establishment, adjustment and development. First, the number of members and departments should be controlled, and disparity diversity should be promoted by attracting members with different clinical titles. Furthermore, founders should try to form a team with a strong/equal-type leadership. Finally, pairwise combinations of leadership types and variety diversity could protect MTs from disbanding. Therefore, this study indicated how a MT should be organized in terms of team diversity and leadership types to avoid TD with strong practicality.

\section{Limitation}

This study has several limitations. First, although the indicator ResponseSpeed could reflect the doctors' attitude toward healthcare service online, measuring the doctors' actual attitude through a survey might be more accurate. Second, we used a cross-sectional design to investigate the relationship between team structure and TD, and further studies could conduct an in-depth study with scientific panel data to confirm the causal relationship. Lastly, we studied the team status from the perspective of members' diversity that focused on the bottom-up effect [50], and future extensions could emphasize the top-bottom effect to explore the influence of MTs on members.

\section{Conclusions}


Our study reveals the micro-foundations of the MT state (i.e., whether to disband) by highlighting team diversity, leadership type and their pairwise combinations. First, a MT online should control team size and departments. Second, members with different clinical titles are conducive to team stability. Third, we propose the pairwise combinations of leadership type and diversity to avoid TD according to the moderating effect. Specifically, a founder should establish a MT with the strong or equal-type leadership and meanwhile control the number of departments. On the contrary, the weak-type leadership should pairwise combine with diverse departments. With regard to the potential mechanisms of these combinations, the strong/equal-type leadership matches less departments, mainly because normative influences dominantly contribute to team stability [51, 52]. However, normative influences of the weak-type leadership is weak and doctors tend to obtain information from others as diagnostic evidences in this setting, so the informational influence from other members functions dominantly [51]. In brief, these points above should be emphasized for the platform and team leaders while setting up or adjusting a MT to avoid TD.

\section{Abbreviations}

MTs: Medical teams;

TD: Team disbandment;

OHCs: Online health communities.

\section{Declarations}

\section{Acknowledgements}

Not applicable.

\section{Funding}

This study was funded by the National Natural Science Foundation of China (NO. 71671073).

\section{Availability of data and material}

The datasets generated and/or analysed during the current study are not publicly available due to the privacy items of the Robots Protocol and since we collected the data from the haodf.com and would use them to write another paper, so data are not public, but are available from the corresponding author on reasonable request.

\section{Authors' contributions}

All authors conceived and designed the study. JL completed the study and analyzed data collected. HW, ZD, RE, ZH and SL wrote and proofread the paper. All authors read and approved the manuscript prior to submission.

\section{Ethics approval and consent to participate}

Not applicable.

\section{Consent for publication}

Not applicable.

\section{Competing interests}

The authors declare no competing interests.

\section{References}

1. Deng Z, Liu S, Hinz O. The health information seeking and usage behavior intention of Chinese consumers through mobile phones. Information Technology \& People. 2015; 28(2):405-423. 
2. García Guzmán J, Saldaña Ramos J, Amescua Seco A, Sanz Esteban A. How to get mature global virtual teams: a framework to improve team process management in distributed software teams. Software Quality Journal. 2010; 18(4):409-435.

3. Bartunek JM, Huang Z, Walsh IJ. The development of a process model of collective turnover. Hum Relat. 2008; 61(1):5-38.

4. Faraj S, Kudaravalli S, Wasko M. Leading collaboration in online communities. MIS Q. 2015; 39(2):393-412.

5. Hoegl M, Gemuenden HG. Teamwork Quality and the Success of Innovative Projects: A Theoretical Concept and Empirical Evidence. Organization Science. 2001; 12(4):435-449.

6. Powell A, Piccoli G, Ives B. Virtual teams: a review of current literature and directions for future research. SIGMIS Database. 2004; 35(1):6-36.

7. Johnson SL, Safadi H, Faraj S. The Emergence of Online Community Leadership. Inf Syst Res. 2015; 26(1):165-187.

8. Lee DS, Lee KC, Seo YW, Choi DY. An analysis of shared leadership, diversity, and team creativity in an e-learning environment. Computers in Human Behavior. 2015; 42:47-56.

9. Li J, Wu H, Deng Z, Lu N, Evans R, Xia C. How professional capital and team heterogeneity affect the demands of online teambased medical service. BMC Medical Informatics and Decision Making. 2019; 19(1):119.

10. Webber SS, Donahue LM. Impact of highly and less job-related diversity on work group cohesion and performance: a metaanalysis. J Manage. 2001; 27(2):141-162.

11. Cohen SG, Bailey DE. What Makes Teams Work: Group Effectiveness Research from the Shop Floor to the Executive Suite. J Manage. 1997; 23(3):239-290.

12. Ilgen DR, Hollenbeck JR, Johnson M, Jundt D. Teams in Organizations: From Input-Process-Output Models to IMOI Models. Annual Review of Psychology. 2005; 56(1):517-543.

13. Ye HJ, Feng Y, Choi BCF. Understanding knowledge contribution in online knowledge communities: A model of community support and forum leader support. Electronic Commerce Research and Applications. 2015; 14(1):34-45.

14. Gennari JH, Weng C, Benedetti J, McDonald DW. Asynchronous communication among clinical researchers: A study for systems design. Int J Med Inform. 2005; 74(10):797-807.

15. Kuziemsky CE, Borycki EM, Purkis ME, Black F, Boyle M, Cloutier-Fisher D, Fox LA, Mackenzie P, Syme A, Tschanz C et al. An interdisciplinary team communication framework and its application to healthcare 'e-teams' systems design. BMC Medical Informatics and Decision Making. 2009; 9(1):43.

16. Ortiz de Guinea A, Webster J, Staples DS. A meta-analysis of the consequences of virtualness on team functioning. Inf Manage. 2012; 49(6):301-308.

17. Wu H, Deng Z. Knowledge collaboration among physicians in online health communities: A transactive memory perspective. Int $J$ Inf Manage. 2019; 49:13-33.

18. Gilson LL, Maynard MT, Jones Young NC, Vartiainen M, Hakonen M. Virtual Teams Research:10 Years, 10 Themes, and 10 Opportunities. J Manage. 2015; 41(5):1313-1337.

19. Baard SK, Rench TA, Kozlowski SWJ. Performance Adaptation:A Theoretical Integration and Review. J Manage. 2014; 40(1):48-99.

20. Ali $\mathrm{Na}$, Tretiakov A, Whiddett $\mathrm{D}$, Hunter I. Knowledge management systems success in healthcare: Leadership matters. Int J Med Inform. 2017; 97:331-340.

21. Ruggieri S, Abbate CS. Leadership Style, Self-Sacrifice, and Team Identification. Soc Behav Pers. 2013; 41(7):1171-1178.

22. Goleman D. Leadership That Gets Results. Harv Bus Rev. 2000; 78(2):78-90.

23. Huang R, Kahai $S$, Jestice R. The contingent effects of leadership on team collaboration in virtual teams. Computers in Human Behavior. 2010; 26(5):1098-1110.

24. Pelled LH, Eisenhardt KM, Xin KR. Exploring the Black Box: An Analysis of Work Group Diversity, Conflict and Performance. Adm Sci Q. 1999; 44(1):1-28.

25. Dulebohn JH, Hoch JE. Virtual teams in organizations. Human Resource Management Review. 2017; 27(4):569-574.

26. Harrison DA, Klein KJ. What's the difference? diversity constructs as separation, variety, or disparity in organizations. Acad Manage Rev. 2007; 32(4):1199-1228.

27. Chae SW, Seo YW, Lee KC. Task difficulty and team diversity on team creativity: Multi-agent simulation approach. Computers in Human Behavior. 2015; 42:83-92. 
28. Chai H-Y, Niu G-F, Lian S-L, Chu X-W, Liu S, Sun X-J. Why social network site use fails to promote well-being? The roles of social overload and fear of missing out. Computers in Human Behavior. 2019; 100:85-92.

29. Jehn KA, Northcraft GB, Neale MA. Why Differences Make a Difference: A Field Study of Diversity, Conflict and Performance in Workgroups. Adm Sci Q. 1999; 44(4):741-763.

30. Wu H, Lu N. Online written consultation, telephone consultation and offline appointment: An examination of the channel effect in online health communities. Int J Med Inform. 2017; 107:107-119.

31. Guo S, Guo X, Fang Y, Vogel D. How Doctors Gain Social and Economic Returns in Online Health-Care Communities: A Professional Capital Perspective. J Manag Inf Syst. 2017; 34(2):487-519.

32. Greenwood BN, Agarwal R, Agarwal R, Gopal A. The When and Why of Abandonment: The Role of Organizational Differences In Medical Technology Life Cycles. Manage Sci. 2017; 63(9):2948-2966.

33. Suttmoeller M. The role of leadership and other factors in the organizational death of domestic far-right extremist organizations(Order No. 3643699). ProQuest Dissertations \& Theses Global A\&I: The Humanities and Social Sciences Collection; Social Science Premium Collection (1609719256) 2014.

34. Hansson M. Organizational closedown and the process of deconstruction and creativity. Culture and Organization. 2017; 23(3):238-256

35. Martins LL, Gilson LL, Maynard MT. Virtual Teams: What Do We Know and Where Do We Go From Here? J Manage. 2004; $30(6): 805-835$.

36. Williams K, Karau S. Social Loafing and Social Compensation: The Effects of Expectations of Co-Worker Performance. J Pers Soc Psychol. 1991; 61(4):570-581.

37. Kerr NL, Bruun SE. Dispensability of member effort and group motivation losses: Free-rider effects. J Pers Soc Psychol. 1983; 44(1):78-94.

38. Nijstad BA: Group performance. New York Psychology Press; 2009.

39. Daniel S, Agarwal R, Stewart KJ. The Effects of Diversity in Global, Distributed Collectives: A Study of Open Source Project Success. Inf Syst Res. 2013; 24(2):312-333.

40. Park B, Overbeck JR, Correll J: Internal Status Sorting in Groups: The Problem of too many Stars. In: Status and Groups. 2005: 169199.

41. Groysberg B, Polzer JT, Elfenbein HA. Too Many Cooks Spoil the Broth: How High-Status Individuals Decrease Group Effectiveness. Organization Science. 2011; 22(3):722-737.

42. Elster J. Social Norms and Economic Theory. J Econ Perspect. 1989; 3(4):99-117.

43. Milgram S. Some Conditions of Obedience and Disobedience to Authority. Hum Relat. 1965; 18(1):57-76.

44. Groves KS, Feyerherm AE. Leader Cultural Intelligence in Context:Testing the Moderating Effects of Team Cultural Diversity on Leader and Team Performance. Group Organ Manag. 2011; 36(5):535-566.

45. Choudhury P, Haas MR. Scope versus speed: Team diversity, leader experience, and patenting outcomes for firms. Strategic Management Journal. 2018; 39(4):977-1002.

46. Buyl T, Boone C, Hendriks W, Matthyssens P. Top Management Team Functional Diversity and Firm Performance: The Moderating Role of CEO Characteristics. Journal of Management Studies. 2011; 48(1):151-177.

47. Der Foo M, Kam Wong P, Ong A. Do others think you have a viable business idea? Team diversity and judges' evaluation of ideas in a business plan competition. J Bus Ventur. 2005; 20(3):385-402.

48. Alin A. Multicollinearity. Wiley Interdiscip Rev Comput Stat. 2010; 2(3):370-374.

49. Burns LR, Wholey DR. Adoption and Abandonment of Matrix Management Programs: Effects of Organizational Characteristics and Interorganizational Networks. Acad Manage J. 1993; 36(1):106-138.

50. Kozlowski SWJ, Klein KJ: A multilevel approach to theory and research in organizations: Contextual, temporal, and emergent processes. In: Multilevel theory, research, and methods in organizations: Foundations, extensions, and new directions. San Francisco, CA, US: Jossey-Bass; 2000: 3-90.

51. Deutsch M, Gerard HB. A study of normative and informational social influences upon individual judgment. The Journal of Abnormal and Social Psychology. 1955; 51(3):629-636. 
52. Luqiu LR, Schmierbach M, Ng Y-L. Willingness to follow opinion leaders: A case study of Chinese Weibo. Computers in Human Behavior. 2019; 101:42-50.

\section{Figures}

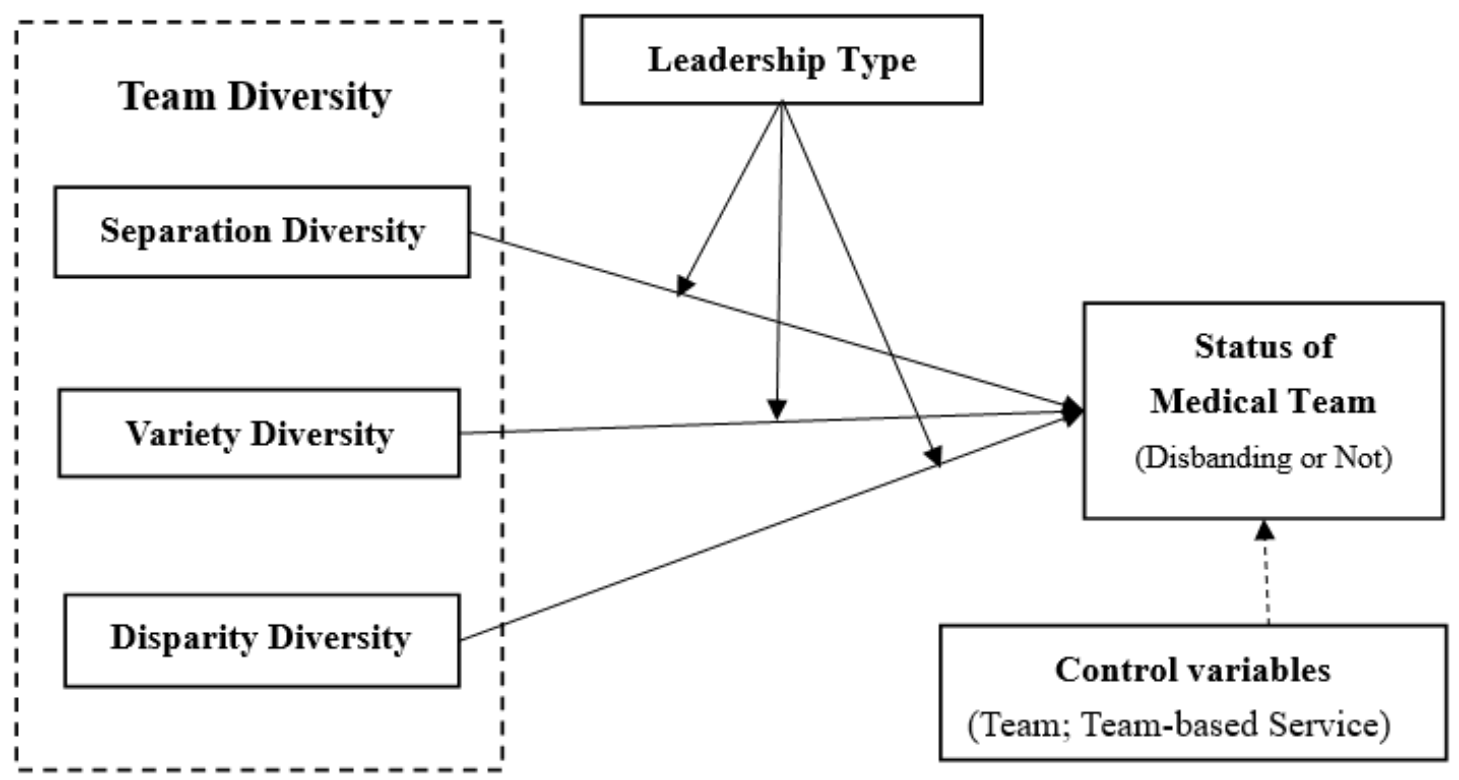

Figure 1. Conceptual Model

Figure 1

Conceptual Model

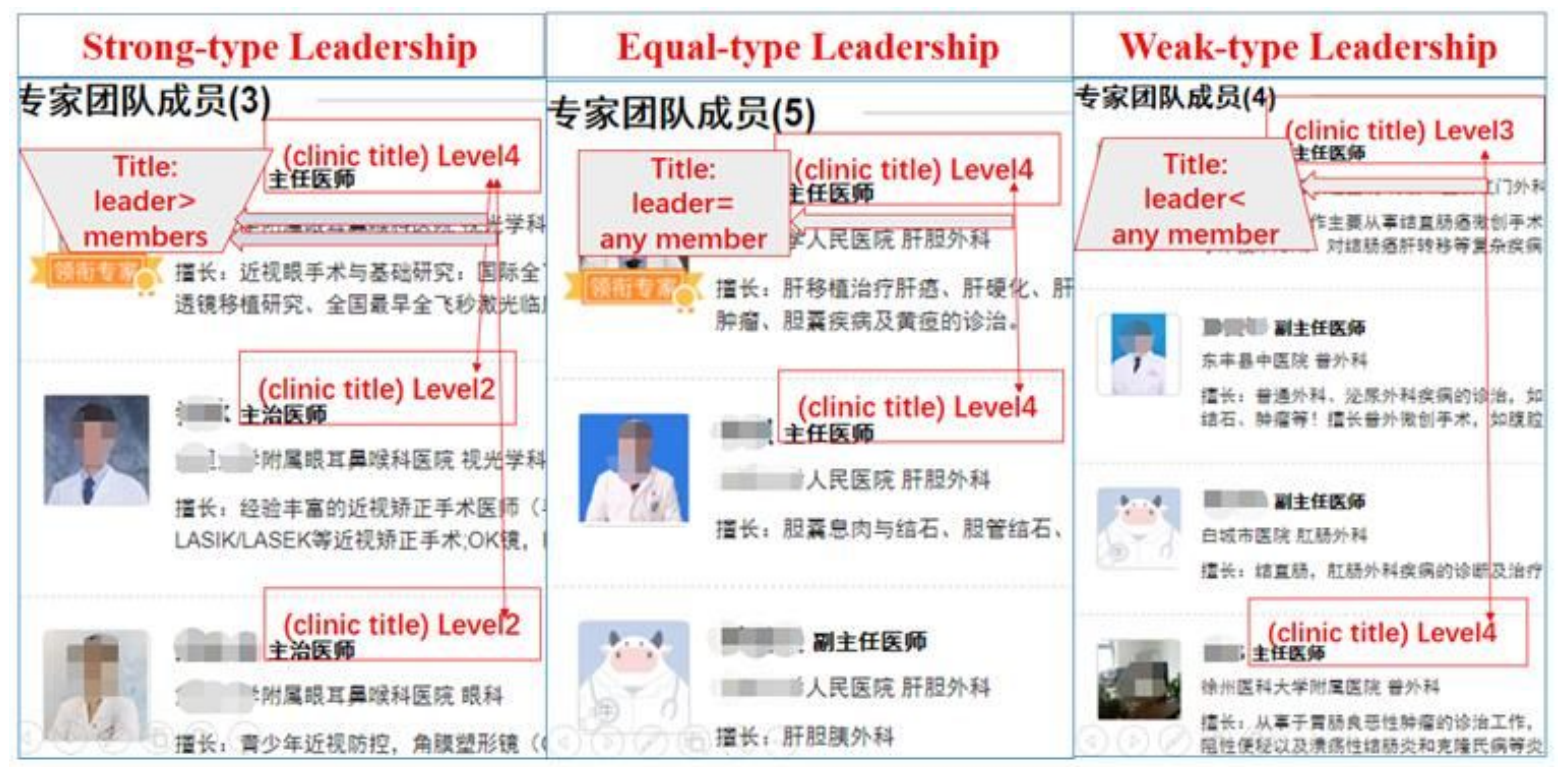

\section{Figure 2 Three types of leadership in online MTs}

Note: The first person is team leader in each MT, and others are members.

\section{Figure 2}

Three types of leadership in online medical teams Note: Team leader is the first person in each MT, and others below are members. 


\section{Supplementary Files}

This is a list of supplementary files associated with this preprint. Click to download.

- Formula.jpg

- Equation.jpg 